\title{
Application of targeted 2D planar chromatography in the control of ginkgolic acids in some herbal drugs and dietary supplements
}

PIOTR MIGAS*

ANNA ROMAŃCZUK

MARTA SZUMACHER

MIROSŁAWA KRAUZE-BARANOWSKA

Department of Pharmacognosy with Medicinal Plants Garden

Medical University of Gdańsk

80-416 Gdańsk, Poland
Accepted April 28, 2019 Published May 22, 2019

\begin{abstract}
Two-step targeted 2D planar chromatographic method (2DTLC) was used in the determination of ginkgolic acids in pharmaceuticals and dietary supplements. The choice of the extraction method and the separation technique was guided by the formulation type (capsule, tablet, tincture) with expected low amounts of ginkgolic acids in the analyzed herbal samples. Separation of ginkgolic acids C15:1 and C17:1 on HPTLC RP18 $W_{254 s}$ was preceded by its separation from the sample matrix on TLC Si60 $\mathrm{F}_{254 \mathrm{~s}}$. Mobile phases consisted of acetonitrile/water/formic acid (80:20:1, $V / V / V)$ and $n$-heptane/ethyl acetate/formic acid (20:30:1, $V / V / V)$, resp. Identification of separated compounds was based on 2D-TLC co-chromatography with reference substances and off-line 2D-TLC $x$ HPLC-DAD-ESI-MS analysis. Quantification of ginkgolic acids C15:1 and C17:1 was conducted densitometrically. Among the analyzed products, the presence of ginkgolic acids was confirmed only in herbal drugs containing $60 \%$ ethanolic tinctures of Ginkgo biloba leaves. The use of TLC in the quantification of ginkgolic acids C15:1 and C17:1 in ginkgo extracts was described for the first time.
\end{abstract}

Keywords: ginkgolic acids, herbal products, 2D planar chromatography, HPLC-DAD-ESI-MS, densitometry

Alkylphenols present in Ginkgo biloba L. (also known as ginkgolic acids) belong to a group of 2-hydroxy-6-alkylbenzoic acid derivatives. Their structures differ in the length of the alkyl chain, the number and the location of double bonds. The main ginkgolic acids, C13:0, C15:1 and C17:2, have been determined both in nutshells and leaves of Ginkgo biloba (1-7). The content of alkylphenols in ginkgo leaves can reach up to $100,000 \mathrm{\mu g} \mathrm{g}^{-1}$.

Ginkgolic acids are considered undesirable compounds of ginkgo leaves extract because of their proven cytotoxic, mutagenic, neurotoxic, hepatotoxic and nephrotoxic activities (8-15). Allergenic properties of Ginkgo biloba leaves extract are also ascribed to the

\footnotetext{
*Correspondence; e-mail: pmig@gumed.edu.pl
} 
presence of these compounds (16). However, studies conducted by Satyan et al. (16) pointed out that, as long as the carboxyl group is present in the structure of ginkgolic acid conjugates, these compounds have no allergenic properties and, on the contrary, exert anti-allergic activity. Moreover, studies conducted on rats had proven that some ginkgolic acid conjugates (namely, $n$-tridecyl-, $n$-pentadecyl-, $n$-heptadecyl-, $n$-pentadecenyl- and $n$-heptadecenylsalicylates) were responsible for anxiolytic activities of ginkgo leaves extracts (16). Other studies highlighted ginkgolic acids as candidates for antitumour drugs because of their ability to induce apoptosis and inhibit cell cycle progression, protein SUMOylation and metastasis (17-19).

In order to reduce the side-effects of ginkgolic acids, it has been established that the concentration in pharmaceuticals should not exceed $5 \mu \mathrm{g} \mathrm{g}^{-1}(20,21)$. Qualitative and quantitative analyses of ginkgolic acids in extracts and products are mostly conducted with the use of high-performance liquid chromatography (HPLC) that is considered more sensitive and accurate than thin-layer chromatography (TLC) (22-25). However, it has been shown that the development of TLC analysis allows the use of TLC interchangeably with HPLC both in qualitative and quantitative surveys $(26,27)$.

Chromatographic conditions enabling TLC separation and the identification of the main ingredients responsible for therapeutic properties (flavonoids and terpene lactones) of ginkgo extract were described in European Pharmacopoeia (28), but also in several published articles $(20,21)$. Separation of ginkgolic acids with the use of TLC in herbal extracts has not been described so far.

The main obstacle in the determination of the composition of herbal extracts is the complex nature that hinders the separation and the determination of single components. Therefore, more and more sophisticated procedures, including multidimensional separation techniques, were employed $(29,30)$. Among them, targeted 2D planar chromatography (2D-TLC), focused on the separation of a single compound or a group of compounds, is the most selective (29). It enables the use of a wide range of adsorbents and also incorporates both concentrating and purification within a single separation of the analyzed sample (29). In this technique, a part of the plate containing the partly separated compound is cut off and the compound is transferred to the second stationary phase for subsequent analysis. The separation can be performed on one or different adsorbents (29-32). If the separation is carried out on different adsorbents, both bilayer plates (33) or graft TLC techniques (34) can be used. Unless the number of types of bilayer TLC plates available on the market is limited, graft TLC allows any types of adsorbents to be combined and thus appears to be the most useful $(29-32,35)$.

In the present study, qualitative and quantitative analyses of the main ginkgolic acids (C15:1 and C17:1) in four drugs and four dietary supplements were performed for the first time with the use of TLC. Targeted 2D planar chromatography, along with HPLC-DAD-ESI-MS analysis, was employed for the determination of ginkgolic acids in the analyzed products.

\section{EXPERIMENTAL}

\section{Chemicals}

Analytical grade solvents were purchased from POCh, Poland (methanol, acetone, ethyl acetate, and ethanol $96 \%$ ), Merck, Germany (n-heptane, acetonitrile, tetrahydrofuran, and formic acid). Deionized water was obtained using the Elix/Synergy system (Merck- 
-Millipore, USA). The standards of ginkgolic acid C15:1 and ginkgolic acid C17:1 were purchased from Merck $\mathrm{GmbH}$ (Germany). Stock solutions $\left(1 \mu \mathrm{g} \mu \mathrm{L}^{-1}\right)$ of reference substances were prepared in methanol and stored at $-20^{\circ} \mathrm{C}$.

\section{Plant material and herbal products}

The analyzed group of herbal products included liquid (60\% ethanolic tinctures of Ginkgo biloba leaves) and solid formulations, tablets and hard capsules, containing dry extracts of ginkgo leaves (Table I). Herbal drugs and dietary supplements were purchased from the pharmacies.

Table I. The analyzed herbal products

\begin{tabular}{cccc}
\hline Symbol & Drug form & $\begin{array}{c}\text { Content of dry ginkgo extract } \\
(\mathrm{mg} \text { in a tablet or a capsule) }\end{array}$ & Status \\
\hline D1 & Hard capsule & 80 & Drug \\
D2 & Tablet & 114 & Drug \\
S1 & Tablet & 60 & Supplement \\
S2 & Tablet & 80 & Supplement \\
S3 & Hard capsule & 80 & Supplement \\
S4 & Tablet & 40 & Supplement \\
T1 & Tincture & $60 \%$ ethanolic extract of G. biloba leaves & Drug \\
T2 & Tincture & $60 \%$ ethanolic extract of G. biloba leaves & Drug \\
\hline
\end{tabular}

Sample preparation

Five $\mathrm{mL}$ of the analyzed tinctures (T1, T2), equaling to $4.675 \mathrm{~g}$ or $4.525 \mathrm{~g}$ of Ginkgo leaves, resp. (Table I), were partitioned with $20 \mathrm{~mL}$ hexane in an Erlenmeyer flask on a magnetic stirrer at room temperature for $15 \mathrm{~min}$. Fifteen $\mathrm{mL}$ of the hexane layer was collected. The solvent was evaporated under reduced pressure at room temperature. The residue, corresponding to $3.506 \mathrm{~g}$ (T1) or $3.394 \mathrm{~g}$ (T2) of plant substance, was dissolved in 2 $\mathrm{mL}$ of methanol and stored in a freezer at $-20^{\circ} \mathrm{C}$.

Five tablets or opened hard capsules (Table I) were weighed and dispersed in $20 \mathrm{~mL}$ of water on a magnetic stirrer for 30 minutes. The suspension was partitioned with $50 \mathrm{~mL}$ of hexane. Forty-five $\mathrm{mL}$ of the hexane layer was collected and the solvent was evaporated under reduced pressure at room temperature. The dry residue was dissolved in $2 \mathrm{~mL}$ of methanol. The samples were stored in a freezer at $-20^{\circ} \mathrm{C}$.

\section{Optimization of chromatographic conditions}

Preliminary separations were performed on silica TLC glass plates (TLC Si60 $\mathrm{F}_{254 \mathrm{~S}}$, Merck, Germany) or silica gel modified with octadecylsilane groups (HPTLC RP18 $\mathrm{WF}_{254{ }^{\prime}}$, Merck). Mobile phases consisting of ethyl acetate, $n$-heptane, acetone, formic acid, acetic acid and 
Table II. Mobile phases tested in the study

\begin{tabular}{|c|c|c|c|}
\hline Code & $\begin{array}{l}\text { Composition of mobile phases tested on } \\
\text { the TLC Si } 60 \mathrm{~F}_{254 \mathrm{~s}} \text { plate }^{\mathrm{a}}\end{array}$ & Code & $\begin{array}{l}\text { Composition of mobile phases tested } \\
\text { on the HPTLC RP18 } \mathrm{WF}_{254 \mathrm{~s}} \text { plate }\end{array}$ \\
\hline NP1 & $\begin{array}{l}\text { ethyl acetate/water/acetic acid/formic } \\
\text { acid (67.5:17.5:7.5:7.5) }\end{array}$ & RP1 & $\begin{array}{l}\text { acetonitrile/formic acid } \\
(100: 1)\end{array}$ \\
\hline NP2 & n-heptane & RP2 & $\begin{array}{l}\text { acetonitrile/water/formic acid } \\
(90: 10: 1)\end{array}$ \\
\hline NP3 & $\begin{array}{l}n \text {-heptane/formic acid } \\
(10: 0.1)\end{array}$ & RP3 & $\begin{array}{l}\text { acetonitrile/water/formic acid } \\
(80: 20: 1)\end{array}$ \\
\hline NP4 & $\begin{array}{l}n \text {-heptane/etyl acetate/formic acid } \\
(9: 1: 0.1)\end{array}$ & RP4 & $\begin{array}{l}\text { acetonitrile/water/formic acid } \\
(70: 30: 1)\end{array}$ \\
\hline NP5 & $\begin{array}{l}n \text {-heptane/ethyl acetate/formic acid } \\
(8: 2: 0.1)\end{array}$ & RP5 & $\begin{array}{l}\text { acetonitrile:water/formic acid } \\
(60: 40: 1)\end{array}$ \\
\hline NP6 & $\begin{array}{l}n \text {-heptane/ethyl acetate/acetone/formic } \\
\text { acid (20:10:10:1.2) }\end{array}$ & RP6 & $\begin{array}{l}\text { acetonitrile:water/formic acid } \\
(80: 20: 0.5)\end{array}$ \\
\hline NP7 & $\begin{array}{l}n \text {-heptane/ethyl acetate/formic acid } \\
(20: 20: 1.2)\end{array}$ & RP7 & $\begin{array}{l}\text { tetrahydrofuran/water/formic acid } \\
(90: 10: 2)\end{array}$ \\
\hline NP8 & $\begin{array}{l}n \text {-heptane/acetone/formic acid } \\
(20: 20: 1.2)\end{array}$ & RP8 & $\begin{array}{l}\text { tetrahydrofuran/water/formic acid } \\
(80: 20: 2)\end{array}$ \\
\hline NP9 & $\begin{array}{l}n \text {-heptane/ethyl acetate:formic acid } \\
(30: 20: 1.2)\end{array}$ & RP9 & $\begin{array}{l}\text { tetrahydrofuran/water/formic acid } \\
(60: 40: 2)\end{array}$ \\
\hline NP10 & $\begin{array}{l}n \text {-heptane/ethyl acetate/formic acid } \\
(20: 30: 1.2)\end{array}$ & RP10 & $\begin{array}{l}\text { tetrahydrofuran/water/formic acid } \\
(70: 30: 2)\end{array}$ \\
\hline NP11 & $\begin{array}{l}n \text {-heptane/ethyl acetate/formic acid } \\
(25: 25: 1)\end{array}$ & RP11 & $\begin{array}{l}\text { tetrahydrofuran/water/acetonitrile/ } \\
\text { formic acid }(40: 40: 20: 2)\end{array}$ \\
\hline NP12 & $\begin{array}{l}n \text {-heptane/ethyl acetate/formic acid } \\
(20: 30: 1)\end{array}$ & & \\
\hline NP13 & $\begin{array}{l}n \text {-heptane/ethyl acetate/formic acid } \\
(15: 35: 1)\end{array}$ & & \\
\hline
\end{tabular}

${ }^{\mathrm{a}} V / V$

water were tested on TLC Si60 $\mathrm{F}_{2545}$ plates (mobile phases NP1-NP13, Table II). Moreover, the samples were separated with the use of mobile phases consisting of acetonitrile, tetrahydrofuran, water and formic acid on HPTLC RP18 $\mathrm{WF}_{254 \mathrm{~s}}$ plates (mobile phases RP1-RP11, Table II). The hexane-partitioned ginkgo tinctures T1 or T2 were applied next to ginkgolic acid C15:1 and ginkgolic acid C17:1 standard with the use of the Hamilton syringe (10 $\mu \mathrm{L})$. Separations were conducted in a horizontal TLC chamber (Camag, Switzerland) at a distance of 40 mm (Table II). Chromatograms were analyzed under UV light ( $\lambda=254$ and $366 \mathrm{~nm})$ (Fig. 1). 


\section{I step}

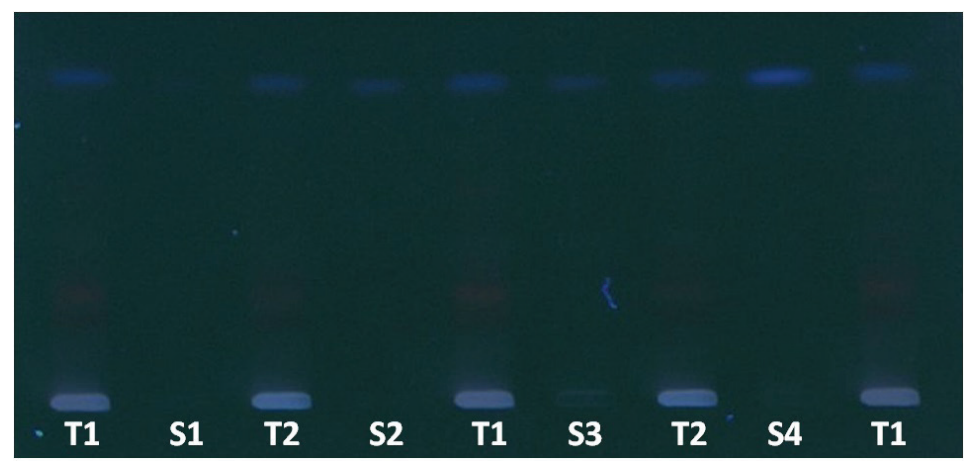

ginkgolic acids

zone

II step

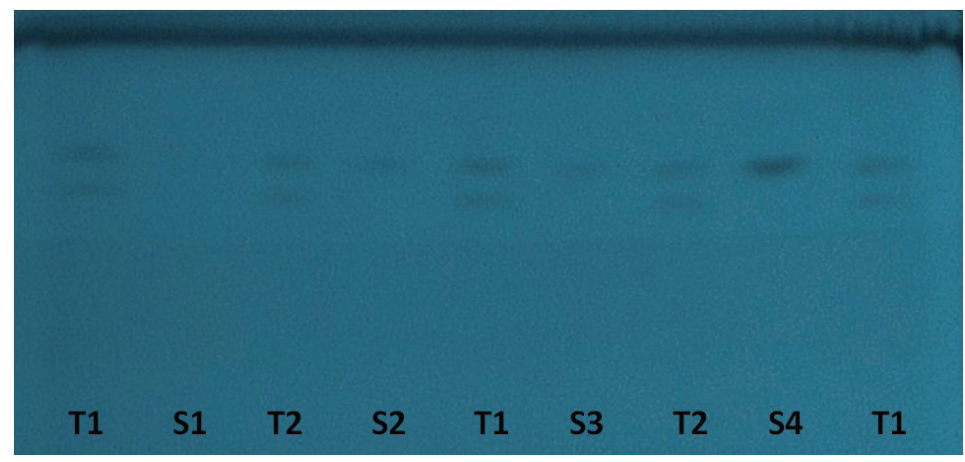

ginkgolic acid 15:1

ginkgolic acid 17:1

Fig. 1. Targeted 2D planar chromatography separation of ginkgolic acids C15:1 and C17:1 (T1, T2 samples of tinctures; S1-4 - increasing amount of ginkgolic acid 15:1).

TLC conditions: I step: adsorbent - TLC Si60 $\mathrm{F}_{254 \mathrm{~s}}$ glass plate $100 \mathrm{~mm} \times 50 \mathrm{~mm}$, UV detection: $\lambda=366$ $\mathrm{nm}$, mobile phase $-n$-heptane/ethyl acetate/formic acid (20:30:1, $V / V / V)$; distance: $40 \mathrm{~mm}$.

II step: HPTLC RP18 $W_{2545}$ glass plate $100 \times 50 \mathrm{~mm}$, UV detection: $\lambda=254 \mathrm{~nm}$, acetonitrile:water/ formic acid $(80: 20: 1, V / V / V)$, distance: $40 \mathrm{~mm}$.

\section{Targeted 2D-TLC separation}

Nine samples were applied as 5-mm bands using Desaga HPTLC-AS 30 applicator (Desaga, Germany) [syringe volume $-10 \mu \mathrm{L}$, sample volume $-4 \mu \mathrm{L}$ (tinctures) or $30 \mu \mathrm{L}$ (solid forms), application speed $-0.33 \mu \mathrm{L} \mathrm{s}^{-1}$, carrier gas - nitrogen] $10 \mathrm{~mm}$ from the low edge and $7 \mathrm{~mm}$ from the side of TLC Si60 $\mathrm{F}_{254 \mathrm{~S}}$ glass plate cut to the proper size $(10 \times 5 \mathrm{~cm})$ with the use of the TLC-cutter (OM Laboratory, Japan).

The separation in the first dimension was conducted on TLC Si60 $\mathrm{F}_{254 \mathrm{~S}}$ glass plate in the twin-through chamber (Camag) conditioned for $15 \mathrm{~min}$ with the mobile phase vapor. The separation was carried out with the use of $n$-heptane/ethyl acetate/formic acid (20:30:1, $V / V / V)$ mixture as a mobile phase at a distance of $40 \mathrm{~mm}$. The developed plate was dried 
at room temperature for $10 \mathrm{~min}$ and analyzed under UV light $(\lambda=366 \mathrm{~nm}$ and $254 \mathrm{~nm})$. The zone of ginkgolic acids (a complex visible as a blue band under UV light) was excised by cutting the plate with a TLC-cutter. The band of ginkgolic acids was transferred to the second glass plate, HPTLC RP18 $\mathrm{WF}_{254 \mathrm{~s}}(10 \times 5 \mathrm{~cm}$, prewashed with methanol and activated at $120^{\circ} \mathrm{C}$ for $30 \mathrm{~min}$ ), in a vertical chamber. Methanol was used as a mobile phase to transfer the band of alkylphenols at a distance of approximately $10 \mathrm{~mm}$. During the transferring time, TLC and HPTLC plates were combined with the use of the device described by Łuczkiewicz et al. (31). TLC plate was then disconnected and HPTLC plate was dried. The separation was continued in the second dimension on HPTLC plate in the horizontal developing chamber (Camag) using acetonitrile/water/formic acid (80:20:1, V/V/V) as a mobile phase at a distance of $40 \mathrm{~mm}$ (Fig. 1). The chromatogram was analyzed densitometrically $(\lambda=320 \mathrm{~nm})$.

\section{Identification of ginkgolic acids}

Preliminary identification of the separated compounds was based on co-chromatography with reference substances. Next, the zones referring to ginkgolic acids C15:1 and C17:1 were scraped off from the plate and extracted with methanol. Qualitative analysis was conducted in the modified HPLC-DAD-ESI-MS system described by Xian-guo et al. (24). The HPLC system (Shimadzu, Japan) consisted of chromatographic pumps (LC 20AD), injector (autosampler SIL 20ACXL), DAD detector (SPD M20A), degasser (DGU 20AS), column oven (CTO 20AC) and interface (CBM 20A). The system was controlled by Labsolutions (Shimadzu) software. The isocratic separation was carried out on a Discovery C18 $\left(150 \mathrm{~mm} \times 2.1 \mathrm{~mm}, 5 \mu \mathrm{m}\right.$, Supelco, USA) column at $45^{\circ} \mathrm{C}$ with the use of a mobile phase of acetonitrile:water/acetic acid (92:7:1, V/V/V; flow rate $\left.0.5 \mathrm{~mL} \mathrm{~min}{ }^{-1}\right)$. The separated compounds were applied directly to LC-ESI-MS detector (LC-MS 2020, Shimadzu). The spectra

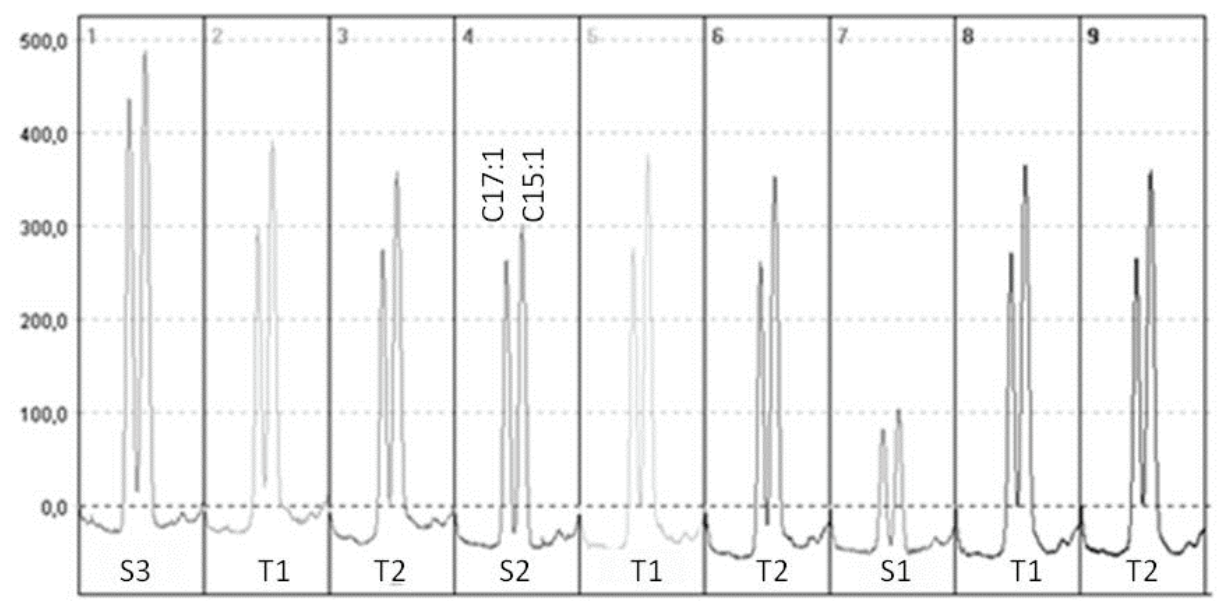

Fig. 2. Densitograms of analyzed samples and ginkgolic acid C15:1 and C17:1 standards separated by the use of targeted 2D planar chromatography (T1, T2 - samples of tinctures; S1-S3 - increasing amount of ginkgolic acid 15:1). For TLC conditions for step I and step II see Fig. 1. 
were acquired in the negative-ion mode: mass range measured: $300-600 \mathrm{~m} / \mathrm{z}$, block temperature: $200^{\circ} \mathrm{C}$, desolvation line (DL) temperature: $250^{\circ} \mathrm{C}$, detector voltage: $1 \mathrm{kV}$, interface voltage: $4.5 \mathrm{kV}$ (Fig. 2).

\section{Quantitative analysis}

Increasing amounts of standard (200, 500 and $1000 \mathrm{ng})$ and two samples in triplicate were separated on each plate. The chromatograms were analyzed densitometrically (CD 60 apparatus controlled by ProQuant 1.03 .300 software (Desaga) and every track was scanned in linear mode (slit height $-0.02 \mathrm{~mm}$, slit width $-6 \mathrm{~mm}$, wavelength $-320 \mathrm{~nm}$, scanning mode - absorbance, the average peak area of four measurements in the spot was recorded).

\section{Preliminary validation}

It included the assessment of detection limit $(L O D)$, quantification limit $(L O Q)$, linearity, instrument precision, repeatability of measurement, inter-day and intra-day precision and recovery (Table III). The limits of detection $(L O D)$ and quantification $(L O Q)$ were determined by analysis of ginkgolic acids standards (50-2000 ng per spot) by using signal-to-noise ratio 3:1 and 10:1, resp. (Table III). The precision of the measurement was calcu-

Table III. Validation parameters for quantitation of ginkgolic acids in herbal products

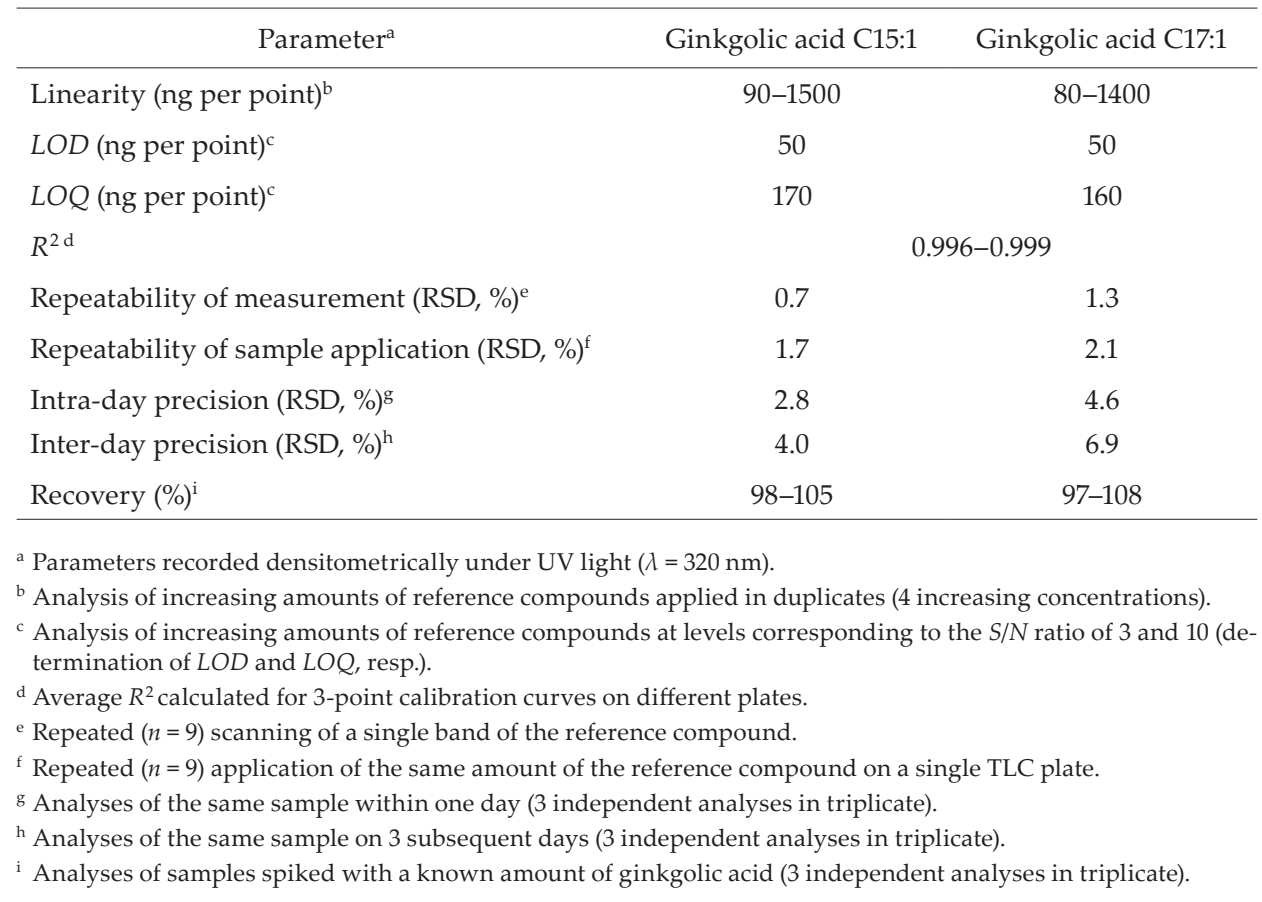


lated basing on the repeated scanning of standards spots $(n=9)$ at $320 \mathrm{~nm}$ (Table III). The assigned range of method linearity showed that it enabled the quantification of ginkgolic acids C15:1 and C17:1 in the range of 90-1500 ng per point and 80-1400 ng per point, resp., with the correlation coefficient of $R^{2}>0.996$ (Table III). Intra-day precision was studied by the analysis of the sample in triplicate on three TLC plates for one day; for inter-day precision, the same analyst repeated analyses on three consecutive days (Table III).

Recovery study based on the standards addition method was used in the assessment of the method accuracy. Ginkgolic acid 15:1 and 17:1 standards were added to the samples at two levels, 25 and $50 \%$ of the analyzed content in the sample, and each was analyzed as described above (Table III). The tinctures (T1 and T2) were used for validation of the developed method.

\section{RESULTS AND DISCUSSION}

\section{Optimization of experimental conditions}

Tinctures and water-dispersed tablets or capsules were partitioned with hexane. The previously described selectivity of hexane towards alkylphenols (despite high levels of polyphenols in ginkgo extracts) (14) and its low boiling point which enabled rapid concentrating of samples at room temperature, made it a useful choice for preparing samples for analyses. Separation of the main ginkgolic acids C15:1 and C17:1 with the use of planar chromatography has not been described so far. In the present study, attempts to separate the compounds were carried out both under normal phase and reverse phase conditions. Glass plates covered with silica gel (TLC Si60 $\mathrm{F}_{254 \mathrm{~s}}$ ) or silica gel modified with octadecylsilane groups (HPTLC RP18 $\mathrm{WF}_{254 \mathrm{~s}}$ ) were used for this purpose.

Separations of ginkgolic acids on TLC glass plates covered with silica gel (TLC Si60 $\mathrm{F}_{254 \mathrm{~s}}$ ) were conducted under normal phase conditions with the use of solvent mixtures consisting of variable proportions of $n$-heptane, ethyl acetate, acetone and formic acid (Table II). It has been noted that the greater the concentration of ethyl acetate or acetone in the mobile phase, the worse the separation of analyzed compounds from interfering substances. For this reason, the addition of $n$-heptane was needed to slow down the migration of the ginkgolic acids zone. However, zones of the separated compounds were tailing during the development which impeded their identification. It has been observed that the addition of formic acid improves the shape of the separated zones with ginkgolic acids. Separation of ginkgolic acids zone from the interfering compounds was achieved under normal phase conditions. The well-separated ginkgolic acids zone was visible $(\lambda=366 \mathrm{~nm})$ near the front of the mobile phase on TLC Si60 $\mathrm{F}_{254 \mathrm{~s}}$ plate developed at a distance of $40 \mathrm{~mm}$ with the use of $n$-heptane/ethyl acetate/formic acid (20:30:1, $V / V / V)$. Nonetheless, none of the thirteen mobile phases tested in the study has enabled the separation of ginkgolic acids C15:1 and C17:1 from one another.

Attempts of ginkgolic acids C15:1 and C17:1 separation were continued under the reverse phase conditions on HPTLC RP18 $\mathrm{WF}_{254 \mathrm{~s}}$ plates at a distance of $40 \mathrm{~mm}$. Mobile phases consisting of variable amounts of acetonitrile, tetrahydrofuran, water and formic acid were tested (Table II). It was noted, that the addition of formic acid in mobile phase improved the shape of ginkgolic acids zones. Ginkgolic acids' zones migrated together in all of the used mobile phases containing tetrahydrofuran (phases RP7-RP11, Table II). In turn, 
increasing the concentration of acetonitrile in the mobile phase enhanced the retention factor of ginkgolic acids zones and hindered the separation. Among the analyzed mobile phases containing acetonitrile (RP1 - RP6, Table II), the mobile phase consisting of acetonitrile/water/formic acid (80:20:1, $V / V / V$, mobile phase RP6) was chosen for further studies. However, the separation of ginkgolic acids was impeded by the accompanied constituents that made the quantitative analysis impossible.

a)

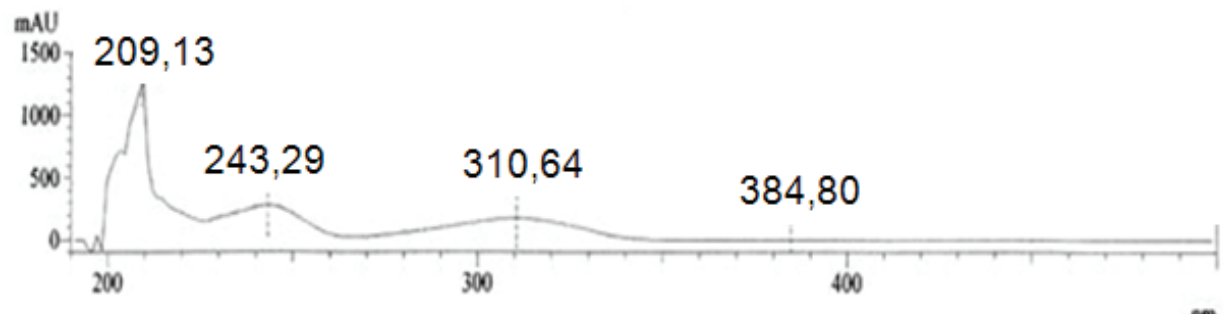

b)

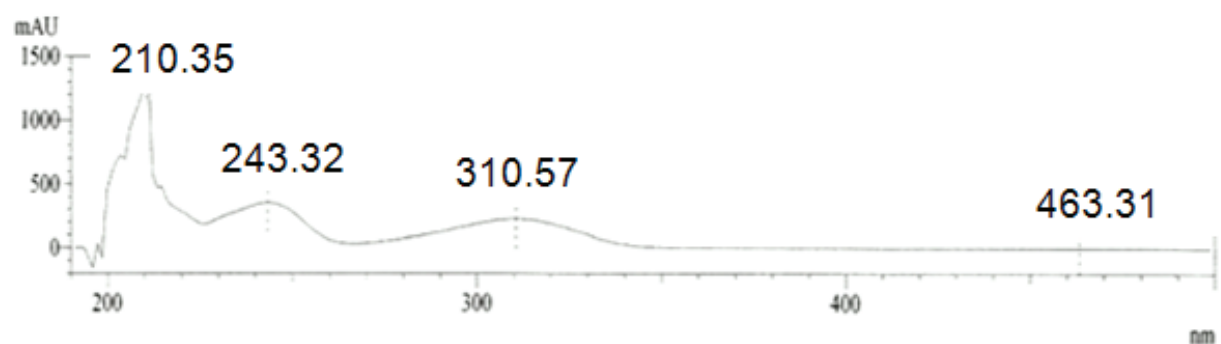

c)

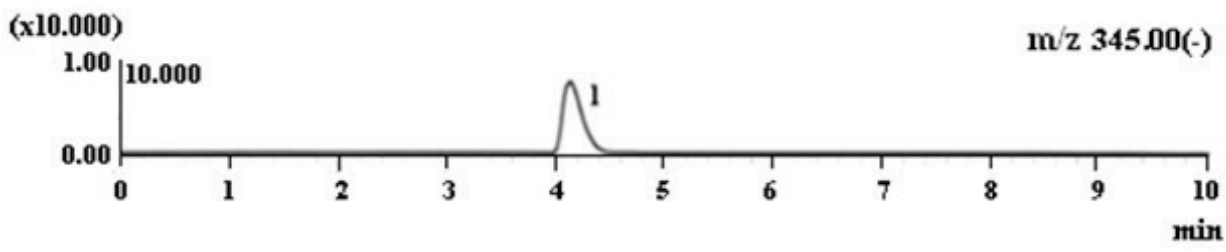

d)

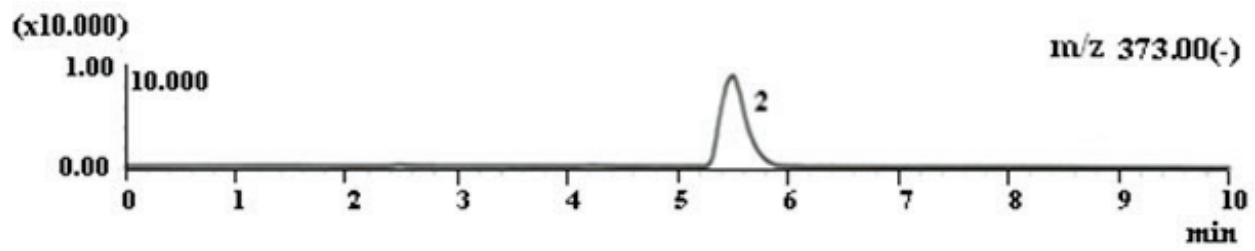

Fig. 3. UV spectra and ion chromatograms of the TLC-separated ginkgolic acids C15:1 and C17:1 recorded by HPLC-DAD-ESI-MS analysis: a) UV spectrum of ginkgolic acid C15:1, b) UV spectrum of ginkgolic acid C17:1, c) ion chromatogram at $\mathrm{m} / \mathrm{z} 345$ and $\mathrm{m} / \mathrm{z} 373$ of ginkgolic acid C15:1, d) ion chromatogram at $\mathrm{m} / \mathrm{z} 345$ and $\mathrm{m} / \mathrm{z} 373$ of ginkgolic acid C17:1. 
For this reason, based on the literature data and our own experiences $(29,30)$, targeted 2D planar chromatography technique combining concentrating, purification, and separation of sample's constituents was used in further studies. Maintaining orthogonal rules, separation of ginkgolic acids was conducted consecutively on TLC Si60 $\mathrm{F}_{254 \mathrm{~s}}$ and HPTLC $\mathrm{RP} 18 \mathrm{WF}_{254 \mathrm{~s}}$ glass plates with the use of the best mobile phases described above (Figs. 1 and 2, Table II). Separation of ginkgolic acids from the accompanying less lipophilic constituents was obtained in the first dimension using $n$-heptane/ethyl acetate/formic acid (20:30:1, $V / V / V)$ on TLC Si60 $\mathrm{F}_{254 \mathrm{~s}}$ plate. Basing on chromatogram analysis under UV light, the fragment of TLC plate containing alkylphenols band was cut off. The final separation of ginkgolic acids was preceded by transferring of this band from TLC Si60 $\mathrm{F}_{2545}$ glass plate on HPTLC RP18 $\mathrm{WF}_{254 \mathrm{~s}}$ glass plate with methanol. Ginkgolic acids C17:1 and C15:1 were separated by the use of the mobile phase consisting of acetonitrile/water/formic acid (80:20:1, $V / V / V$ ) to an extent that allowed their qualitative and quantitative analysis (Figs. 1,2).

\section{Analytical parameters}

The assigned range of method linearity showed that it enabled the quantification of ginkgolic acids C15:1 and C17:1 in the range of 90-1500 ng per point and 80-1400 ng per point, resp., with the correlation coefficient of $R^{2}>0.996$ (Table III). However, the presence of accompanied compounds made the quantification of less than $170 \mathrm{ng}$ per spot of C15:1 and less than $160 \mathrm{ng}$ per spot of C17:1 impossible (Table III).

Meanwhile, the accompanying substances have limited the application of greater volumes of analyzed samples due to the adsorbent overloading and tailing of constituent zones during the TLC chromatogram development. It was found out, that up to $30 \mu \mathrm{L}$ of extract from tablets or capsules could be applied on the TLC plate with no influence on the separation of ginkgolic acids. This volume limitation enabled the quantification of no less than $10 \mu \mathrm{g} \mathrm{g}^{-1}$ of ginkgolic acid C15:1 or C17:1 in the analyzed products.

\section{Analytical application}

The identification of ginkgolic acids bands was based on 2D-TLC co-chromatography along with HPLC-ESI-MS analysis in the presence of reference substances (25). It was found out that ginkgolic acids C15:1 and C17:1 were dominant alkylphenols in the analyzed tinctures T1 and T2 of ginkgo leaves (Figs. 1-3). Ginkgolic acids were not detected in tablets or capsules.

The quantitative analysis was conducted densitometrically with the use of the developed targeted 2D planar chromatography method. The analyzed samples were applied on each plate next to increasing amounts of the reference substances in order to reduce the influence of variable chromatographic conditions (e.g., humidity, temperature, atmospheric pressure) on the separation of the compounds. The procedure of ginkgolic acids' quantification had been preliminary validated (Table III). Due to the fact that the developed 2DTLC method combined the purification and the separation of the analyzed samples, the procedure of sample preparation was simplified and therefore shortened. As in any TLC, the solvent consumption analysis was significantly lower in comparison with HPLC as two samples were determined during a single separation.

Ginkgolic acids C15:1 and C17:1 were determined in the analyzed tinctures T1 and T2; these products contained similar quantities of ginkgolic acids, ranging 209 to $283 \mathrm{mg} \mathrm{g}^{-1}$. 
P. Migas et al.: Application of targeted 2D planar chromatography in the control of ginkgolic acids in some herbal drugs and dietary supplements, Acta Pharm. 69 (2019) 201-213.

Table IV. Content of ginkgolic acids C15:1 and C17:1 in the analyzed tinctures

\begin{tabular}{ccc}
\hline \multirow{2}{*}{ Sample } & \multicolumn{2}{c}{ Content $\left(\mu \mathrm{g} \mathrm{g}^{-1}\right)^{\mathrm{a}}$} \\
\cline { 2 - 3 } & Ginkgolic acid C15:1 & Ginkgolic acid C17:1 \\
\hline T1 & $257.33 \pm 6.20$ & $281.68 \pm 5.46$ \\
T2 & $283.83 \pm 7.35$ & $209.33 \pm 9.67$ \\
\hline
\end{tabular}

${ }^{a}$ Mean \pm SD (analysis in triplicate).

Based on the quantitative data, the concentration of ginkgolic acid C15:1 and C17:1 in $60 \%$ ethanolic extracts of ginkgo leaves was significantly greater than the acceptable level of 5 $\mu \mathrm{g} \mathrm{g}^{-1}$, specified in the European Pharmacopoeia for ginkgo dry extract (Table IV) (28). Our results are in accordance with Schwabe's patent (14) and are pointing out that the concentration of ginkgolic acids in commercial extracts may reach $320 \mu^{g} \mathrm{~g}^{-1}$ (14).

\section{CONCLUSIONS}

The aim of this study was to quantitatively and qualitatively analyze the ginkgolic acids present in herbal products with the use of the planar chromatography technique. The developed targeted 2D planar chromatography combined concentration, purification, and separation of the main ginkgolic acids C15:1 and C17:1. This study has proven that planar chromatography is useful, not only for qualitative, but also for quantitative analysis of ginkgolic acids in mono- and multi-component herbal products.

Acknowledgments. - This project was supported by the Ministry of Science and Higher Education Republic of Poland from the quality-promoting subsidy under the Leading National Research Centre (KNOW) programme 2012-2017.

\section{REFERENCES}

1. Z. Huang, Y. Xu, Y. Huang, Ch. Liu, K. Jiang and L. Wang, Rapid determination of ginkgolic acids in Ginkgo biloba kernels and leaves by direct analysis in real time-mass spectrometry, J. Sep. Sci. 40 (2017) 4857-4864; https://doi.org/10.1002/jssc.201700626

2. H. Jaggy and E. Koch, Chemistry and biology of alkylphenols from Ginkgo biloba L, Pharmazie 52 (1997) 735-738.

3. T. A. Van Beek and M. S. Wintermans, Preparative isolation and dual column high-performance liquid chromatography of ginkgolic acids from Ginkgo biloba, J. Chromatogr. A 930 (2001) 109-117; https://doi.org/10.1016/S0021-9673(01)01194-3

4. J. Deguchi, Y. Hasegawa, A. Takagi, S. Kutsukake, M. Kono, Y. Hirasawa, P. C. Wong, T. Kaneda and H. Morita, Four new ginkgolic acids from Ginkgo biloba, Tetrahedron Lett. 55 (2014) 3788-3791; https://doi.org/ 10.1016/j.tetlet.2014.05.076

5. M. Wang, J. Zhao, B Avula, Y.-H. Wang, C. Avonto, A. G. Chittiboyina, P. L. Wylie, J. F. Parcher and I. A. Khan, High-resolution gas chromatography/mass spectrometry method for characterization and quantitative analysis of ginkgolic acids in Ginkgo biloba plants, extracts, and dietary supplements, J. Agric. Food Chem. 62 (2014) 12103-12111; https://doi.org/10.1021/jf503980f 
6. D. Wang, H. Zhu, M. Li, X. Song, H. Yan, J. Yu and X. Wang, An efficient method for the preparative separation and isolation of ginkgolic acids from the sarcotesta of Ginkgo biloba L by pH-zonerefining counter-current chromatography coupled with inner-recycling mode, Ind. Crop. Prod. 126 (2018) 69-75; https://doi.org/10.1016/j.indcrop.2018.09.034

7. X. Yao, G.-S. Zhou, Y.-P. Tang, Y.-F. Qian, H.-L. Guan, H. Pang, S. Zhu, X. Mo, S.-L. Su, C. Jin, Y. Qin, D.-W. Qian and J.-A. Duan, Simultaneous quantification of flavonol glycosides, terpene lactones, biflavones, proanthocyanidins, and ginkgolic acids in Ginkgo biloba leaves from fruit cultivars by ultrahigh-performance liquid chromatography coupled with triple quadrupole mass spectrometry, BioMed. Res. Int. 2013 (2013) Article ID 582591 (11 pages); https://doi. org/10.1155/2013/582591

8. B. Ahlemeyer, D. Selke, C. Schaper, S. Klumpp and J. Krieglstein, Ginkgolic acids induce neuronal death and activate protein phosphatase type-2C, Eur. J. Pharmacol. 430 (2001) 1-7; https://doi. org/10.1016/S0014-2999(01)01237-7

9. G. Baron-Ruppert and N. P. Luepke, Evidence for toxic effects of alkylphenols from Ginkgo biloba in the hen's egg test (HET), Phytomedicine 8 (2001) 133-138; https://doi.org/10.1078/0944-7113-00022

10. H. Hecker, R. Johannisson, E. Koch and C. P. Siegers, In vitro evaluation of the cytotoxic potential of alkylphenols from Ginkgo biloba L, Toxicology 177 (2002) 167-177; https://doi.org/10.1016/S0300483X(02)00189-0

11. L. Jiang, Z. H. Si, M. H. Li, H. Zhao, Y. H. Fu, Y. X. Xing, W. Hong, L. Y. Ruan, P. M. Li and J. S. Wang, ${ }^{1} \mathrm{H}$ NMR-based metabolomics study of liver damage induced by ginkgolic acid (15:1) in mice, JPBA 136 (2017) 44-54; https://doi.org/10.1016/j.jpba.2016.12.033

12. N. Mei, X. Guo, Z. Ren, D. Kobayashi, K. Wada and L. Guo, Review of Ginkgo biloba-induced toxicity, from experimental studies to human case reports, J. Environ. Sci. Health C 35 (2017) 1-28; https://doi.org/10.1080/10590501.2016.1278298

13. Y. Qian, Y. Peng, E. Shang, M. Zhao, L. Yan, Z. Zhu, J. Tao, S. Su, S. Guo and J. Duan, Metabolic profiling of the hepatotoxicity and nephrotoxicity of ginkgolic acids in rats using ultra-performance liquid chromatography-high-definition mass spectrometry, Chem.-Biol. Interact. 273 (2017) 11-17; https://doi.org/10.1016/j.cbi.2017.05.020

14. W. Schwabe, Extract from Ginkgo biloba leaves, its method of preparation and pharmaceuticals containing the extract, E. U. Pat. EP0431535 B1, 1994.

15. C. Ude, M. Schubert-Zsilavecz and M. Wurglics, Ginkgo biloba extracts: A review of the pharmacokinetics of the active ingredients, Clin. Pharmacokin. 52 (2013) 727-749; https://doi.org/ 10.1007/ s40262-013-0074-5

16. K. S. Satyan, A. K. Jaiswal, S. Ghosal and S. K. Bhattacharya, Anxiolytic activity of ginkgolic acid conjugates from Indian Ginkgo biloba, Psychopharmacology 136 (1998) 148-152.

17. I. Fukuda, A. Ito, G. Hirai, S. Nishimura, H. Kawasaki, H. Saitoh, K. Kimura, M. Sodeoka and M. Yoshida, Ginkgolic acid inhibits protein SUMOylation by blocking formation of the E1-SUMO intermediate, Chem. Biol. 16 (2009) 133-140; https://doi.org/10.1016/j.chembiol.2009.01.009

18. L. Qiao, J. Zheng, X. Jin, G. Wei, G. Wang, X. Sun and X. Li, Ginkgolic acid inhibits the invasiveness of colon cancer cells through AMPK activation, Oncol. Lett. 14 (2017) 5831-5838; https://doi. org/10.3892/ol.2017.6967

19. C. Zhou, X. Li, W. Du, Y. Feng, X. Kong, Y. Li, L. Xiao and P. Zhang, Antitumor effects of ginkgolic acid in human cancer cell occur via cell cycle arrest and decrease the Bcl-2/Bax ratio to induce apoptosis, Chemotherapy 56 (2010) 393-402; https://doi.org/10.1159/000317750

20. A. Gawron-Gzella, P. Marek, J. Chanaj and I. Matławska, Comparative analysis of pharmaceuticals and dietary supplements containing extracts from the leaves of Ginkgo biloba L, Acta Pol. Pharm. 67 (2010) 335-343.

21. S. Kressmann, W. E. Müller and H. H. Blume, Pharmaceutical quality of different Ginkgo biloba brands, J. Pharm. Pharmacol. 54 (2002) 661-669; https://doi.org/10.1211/0022357021778970 
22. N. Fuzzati, R. Pace and F. Villa, A simple HPLC-UV method for the assay of ginkgolic acids in Ginkgo biloba extracts, Fitoterapia 74 (2003) 247-256; https://doi.org/10.1016/S0367-326X(03)00040-6

23. K. Ndjoko, J. L. Wolfender and K. Hostettmann, Determination of trace amounts of ginkgolic acids in Ginkgo biloba L. leaf extracts and phytopharmaceuticals by liquid chromatography-electrospray mass spectrometry, J. Chromatogr. B 744 (2000) 249-255.

24. H. Xian-Guo, M. W. Bernart, G. S. Nolan, L. Long-Ze and M. P. Lindenmaier, High-performance liquid chromatography-electrospray ionization-mass spectrometry study of ginkgolic acid in the leaves and fruits of the ginkgo tree (Ginkgo biloba), J. Chromatogr. Sci. 38 (2000) 169-173.

25. R. Wang, Y. Kobayashi, Y. Lin, H. W. Rauwald, J. Yao, L. Fang, H. Qiao and K. Kuchta, HPLC quantification of all five ginkgolic acid derivatives in Ginkgo biloba extracts using 13:0 ginkgolic acid as a single marker compound, Planta Med. 81 (2015) 71-78; https://doi.org/10.1055/s-0034-1383312

26. C. M. Loescher, D. W. Morton, S. Razic and S. Agatonovic-Kustrin, High performance thin layer chromatography (HPTLC) and high performance liquid chromatography (HPLC) for the qualitative and quantitative analysis of Calendula officinalis - advantages and limitations, J. Pharm. Biomed. Anal. 98 (2014) 52-59; https://doi.org/10.1016/j.jpba.2014.04.023

27. B. H. Patel, B. N. Suhagia, M. M. Patel and J. R. Patel, Simultaneous estimation of pantoprazole and domperidone in pure powder and a pharmaceutical formulation by high-performance liquid chromatography and high-performance thin-layer chromatography methods, J. AOAC Int. 90 (2007) 142-146.

28. European Pharmacopoeia 8.0, Council of Europe, Strasbourg 2014.

29. Sz. Nyiredy, Planar Chromatography. A Retrospective View for the Third Millennium, Springer Scientific Publisher, Budapest 2001.

30. F. Rabel, J. Sherma, A review of advances in two-dimensional thin-layer chromatography, J. Liq. Chromatogr. Rel. Technol. 39 (2016) 627-639; https://doi.org/10.1080/10826076.2016.1214844

31. M. Łuczkiewicz, P. Migas, A. Kokotkiewicz, M. Walijewska and W. Cisowski, Two-dimensional TLC with adsorbent gradient for separation of quinolizidine alkaloids in the herb and in-vitro cultures of several Genista species, JPC 17 (2004) 89-94; https://doi.org/10.1556/JPC.17.2004.2.2

32. P. Migas and M. Świtka, TLC with an adsorbent gradient for the analysis of taxol in Taxus baccata L, JPC 23 (2010) 286-288; https://doi.org/10.1556/JPC.23.2010.4.9

33. M. Krauze-Baranowska, I. Malinowska and J. Skwierawska, TLC of flavonol truxinic esters from Pseudotsuga menziesii, JPC-Modern TLC 15 (2002) 437-441.

34. M. Glensk, U. Sawicka, I. Mazol and W. Cisowski, 2DTLC-graft planar chromatography in the analysis of a mixture of phenolic acids, JPC-Modern TLC 15 (2002) 463-465.

35. M. Waksmudzka-Hajnos, J. Sherma and T. Kowalska, Thin Layer Chromatography in Phytochemistry, CRC Press, Boca Raton 2011. 